\title{
Family attitudes about and experiences with medical cannabis in children with cancer or epilepsy: an exploratory qualitative study
}

\author{
Marissa Gibbard BSc, Dawn Mount BA ECE, Shahrad R. Rassekh MD MHSc, Harold (Hal) Siden MD MHSc
}

\section{Abstract}

Background: Cannabis is legal for recreational and medical use in Canada. Our aim was to explore family experiences using medical cannabis for children with severe conditions in the context of legalization.

Methods: We conducted a qualitative study using semistructured interviews between April and July 2019. Participants were parents of children attending BC Children's Hospital oncology or palliative care clinics, recruited through posters, emails or referral. Participants were included if they spoke English and their child used any type of cannabis for medical purposes. Interviews included openended questions about the child's cannabis use. Interviews were recorded and transcribed, and thematic analysis was performed using qualitative description.

Results: Ten interviews were completed with 9 mothers and 1 mother-father pair. The age range of the children was 22 months to 16 years. The primary reasons for cannabis use were epilepsy ( 6 children) or chemotherapy management (4 children). Five major themes were identified. 1) Child and family context, and cannabis as a last resort: children were seen as severely ill; parents sought cannabis out of desperation and responsibility to their child. 2) Varied information sources informed decision-making: parents lacked resources from health care providers and sought support from social media, industry and other families. 3) Cannabis as an ambiguous medicine: cannabis was viewed as both a serious drug that doctors should prescribe and as a natural alternative health product, safe to pursue alone. 4) Perceived effects: parents perceived medical benefits with few concerns about adverse effects. 5) Legal and financial challenges: parents were willing to obtain cannabis despite high costs and uncertain legality.

Interpretation: Parents of children with severe conditions pursued medical cannabis despite obstacles and needed unbiased information to access alone. Scientific investigation is needed to develop pediatric medical guidelines to inform decisions.

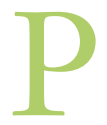

ediatric use of medical cannabis entered widespread public consciousness in 2013, when the CNN television network aired Weed, a documentary highlighting its therapeutic benefits in children with severe epilepsy. ${ }^{1}$ Since then, pediatric medical cannabis has continued to gain societal and scientific attention..$^{2-5}$ Cannabis contains 2 main cannabinoids with proposed medicinal effects: cannabidiol (CBD) and delta-9-tetrahydrocannabinol (THC). ${ }^{6}$ Cannabidiol reduces seizure frequency and duration in children with treatmentresistant epilepsy, ${ }^{7}$ specifically Dravet syndrome; ${ }^{8-10}$ THC is known to have antiemetic, appetite-stimulant and analgesic effects useful in cancer treatment. ${ }^{11-15} \mathrm{We}$ use the term medical cannabis for any combination of CBD and THC.

In 2018, Canada became the second nation to legalize cannabis for both recreational and medical use. Products under pharmaceutical regulations (Controlled Drugs and Substances Act [S.C 1996, c. 19]) are available via prescription as semisynthetic drugs ${ }^{16}$ or highly purified plant-derived drugs. ${ }^{17}$ Nonpharmaceutical, standardized cannabis extracts are available with medical authorization from more than 150 licensed producers, (Cannabis Act [S.C. 2018, c. 16]). Additionally, adults may obtain cannabis intended for recreational use, without medical authorization, from retail stores, called dispensaries, or black market sources. ${ }^{18,19}$ Provenance of cannabis from dispensaries is often unknown. Cannabis can also be grown at home.

There is a lack of robust evidence to guide cannabis practices across pediatric medical disciplines. ${ }^{2,20,21}$ The Canadian Paediatric Society does not support its use, except on a carefully considered, case-by-case basis, citing limited evidence and potential harms. ${ }^{2}$ Thus, in Canada, use of medical cannabis is most known in children with severe conditions. Few

Competing interests: None declared.

This article has been peer reviewed.

Correspondence to: Hal Siden, hsiden@bcchr.ca

CMAJ Open 2021. DOI:10.9778/cmajo.20200212 
studies have explored family attitudes about or experiences with pediatric medical cannabis; ;,22,23 most have focused on treatment types and parent-reported outcomes. ${ }^{24-28}$ Data are lacking on family experiences in Canada. In this qualitative study, our objective was to explore family experiences using medical cannabis for children with severe conditions in Canada, to set the stage for further research.

\section{Methods}

\section{Study design and setting}

Our qualitative study design used semistructured interviews, which were conducted between April and July 2019 at the BC Children's Hospital Oncology Clinic and the Canuck Place Children's Hospice in Vancouver, British Columbia. Palliative care, in which incidence of epilepsy is high, and oncology were chosen to represent areas of known pediatric cannabis use. ${ }^{4,11}$ This offered varied clinic experiences while representing patients of comparable condition severity.

\section{Participants}

Participants were parents of patients (age $<18$ yr) who currently or previously used any form of cannabis for medical purposes. We defined medical purposes as a primary intention to improve any aspect of the child's medical condition. Participants were excluded if they did not speak English or if their child had not used medical cannabis.

Participants were recruited between April and July 2019, through advertisements on posters and e-newsletters at participating clinics, or by referral from a clinician. Interested families were asked to contact the lead researcher (M.G.) for more information and for eligibility screening. Informed consent was obtained before participation. We chose our sample size in consultation with qualitative experts to gather information from a variety of families, and based on study team recognition of the small number of cannabis users at the study sites and sensitivity of subject matter.

\section{Data collection}

An interview guide (Appendix 1, available at www.cmajopen.ca/ content/9/2/E563/suppl/DC1), developed by the study team (H.S. and S.R.R.), outlined open-ended questions regarding the child's cannabis use. Questions were chosen to capture topics lacking evidence, based on a scoping review completed by our team (S.R.R. and H.S.). ${ }^{7}$ A librarian working with the team conducted the MEDLINE search for experiences, attitudes and opinions of caregivers for pediatric patients using medical cannabis. The search found very limited data., ${ }^{3,22,23}$

Interviews were conducted in person (private offices) or by phone, by female researchers (M.G. or D.M.) with no prior relationship to participants. Interviewers had previous qualitative interview experience or training. The interviewer documented observations (e.g., participant crying) and audiorecorded interviews. Participants were interviewed once; recruitment continued until reaching the predetermined sample size of 10 participants. No participants withdrew from the study.

\section{Data analysis}

Interviews were transcribed, deidentified and added to NVivo 12 software for analysis (M.G.). ${ }^{29}$ Thematic analysis was performed iteratively during data collection, using a qualitative descriptive approach. ${ }^{30}$ Qualitative description was used to focus on formally describing informational content of the interviews, given the limited scientific exploration in this area. One researcher (M.G.) and an assistant independently coded interview content into categories that arose from the data, without predetermined themes. Categories were organized into themes to describe salient experiences across participants and highlight areas for future investigation. Subthemes were developed to exemplify categories for interpreting overarching themes. Analyses were compared, discrepancies discussed with H.S., and themes reorganized as consensus was reached by M.G. and the assistant. Final analyses were performed on the entire data set with an additional interpretive step. H.S. reviewed 2 interviews independently to confirm categories, and overarching themes were restructured with reorganization of subtheme categories to convey richer description of experiences (M.G.).

\section{Ethics approval}

This study was approved by the University of British Columbia Children's and Women's Research Ethics Board (H18-01112).

\section{Results}

We conducted 10 interviews (9 mothers and 1 mother-father pair). The interviews lasted 1 hour each. Parent and patient characteristics are described in Table 1. Management of epilepsy, cancer pain or chemotherapy adverse effects (nausea and appetite) were primary reasons for cannabis use. Other reasons included treating anxiety and reducing other medications. Two parents of children with cancer also hoped for antitumour effects. Product sources and types are described in Table 2. Products included edible oils with varied cannabinoid concentrations, nasal spray and dried cannabis for smoking. Duration of use ranged from 2 weeks to 4 years.

\section{Family experiences}

Parents reported obstacles to accessing medical cannabis, and reflected on decision-making, perceived effects and challenges. We identified 5 overarching themes and 10 subthemes (Table 3) across interviews.

\section{Child and family context, and cannabis as a last resort}

This theme included reasons for cannabis use based on diagnosis severity (subtheme: child's condition and severity). Children were perceived as being severely ill, so trying nonstandard treatments was considered warranted. Children took multiple medications or treatments in addition to cannabis, such as undergoing chemotherapy for a second cancer relapse. The child's medical context highlighted urgency of family circumstances; parents sought cannabis "out of 


\begin{tabular}{|lc|}
\hline \multicolumn{2}{|l|}{ Table 1: Patient and participant (parent) characteristics } \\
\hline Characteristic & No. ${ }^{*}$ \\
\hline Patient sex & 5 \\
\hline Female & 5 \\
\hline Male & \\
\hline Patient age & $9.4 \pm 4.9$ \\
\hline Mean \pm SD, yr & 42 mo to 16 yr \\
\hline Range & 6 \\
\hline Patient medical condition \\
\hline Cancer \\
\hline Neurologic/neurogenetic \\
\hline Primary reason for patient cannabis use \\
\hline Chemotherapy adverse effects \\
\hline Epilepsy \\
\hline Participating parent \\
\hline Mother \\
\hline Mother-father pair \\
\hline $\begin{array}{l}\text { Note: SD = standard deviation. } \\
\text { *Unless stated otherwise. }\end{array}$ \\
\hline
\end{tabular}

desperation" when traditional medications were not as effective as desired.

This theme also included parents' perceptions of social pressures and willingness to overlook stigma to help their child when nothing else was working (subtheme: social acceptance v. stigma). Parents described pressure both to use and not use cannabis. However, outside pressures did not affect their decision-making, given the severity of circumstances. They described ignoring external influences to do what was best for their child. Pressure not to pursue cannabis from unsupportive doctors was not a deterrent; parents turned to community sources or switched doctors. Within their communities, most families reported social acceptance, with pressure to use medical cannabis, and were advocates themselves.

Because of the severity of the child's condition, families used cannabis as a last resort, as evidenced by their willingness to overlook pressures. This conveyed a sense of parental love (subtheme: parental love and responsibility), as parents described the responsibility to try anything to improve their child's quality of life, despite consequences. Before legalization, one mother had visited multiple health care providers over many months in hope of finding someone willing to authorize use, ultimately accepting legal risks to access products on her own from outside of Canada.

\section{Varied information sources informed decision- making}

This theme encompassed the myriad informational sources that parents relied on. Parents received information about medical benefits, product types and practicalities through some health care providers and many informal sources (friends, family, media, online advocacy groups and dispensary employees) (subtheme: suppliers and advocates; subtheme: communication with health care providers).

Despite reporting a mass of information online, parents described a substantial lack of trusted medical information, especially if health care providers were unsupportive (subtheme: lack of reliable information). Given the lack of resources, parents had difficulty deciding on cannabis sources. To obtain cannabis for children legally, parents needed doctors to provide authorization for licensed producers. However, parents indicated that local or online dispensaries offered easy access; they could discuss needs with staff and make purchases with few roadblocks. In the absence of other information, trust in product contents and consistency, along with prices and reputation, were crucial when choosing suppliers.

Parents had to rely on themselves as experts on cannabis treatments (subtheme: practicalities and parent expertise). Usual information sources, such as physicians or nurses, typically could not provide guidance. Parents conveyed precise details about contents of products, even when using unregulated products. They described changing cannabis dose over time, and navigated practicalities of administration for their child's individual needs, such as finding vehicles to administer cannabis by gastrostomy tube.

Lack of scientific evidence was a substantial barrier when searching for reliable information (subtheme: need for research). Parents felt they were experimenting with cannabis treatments. They needed to learn through trial and error, and their own observations because of an understanding that

Table 2: Source and type of cannabis products

\begin{tabular}{|llc|}
\hline Source & \multicolumn{1}{c|}{$\begin{array}{c}\text { No. of participants } \\
n=10\end{array}$} & 3 \\
\hline Community dispensary or online & $\begin{array}{l}\text { Nonstandardized products† (no medical } \\
\text { authorization needed) }\end{array}$ & 5 \\
\hline Licensed medical producer & $\begin{array}{l}\text { Nonpharmaceutical, standardized extracts } \\
\text { (licensed products requiring medical authorization) }\end{array}$ & 2 \\
\hline Both community dispensary and medical producer & Both nonstandardized and licensed products & \\
\hline $\begin{array}{l}{ }^{*} \text { Categorization based on Pawliuk et al. } \\
\text { †Refers to homemade or store-bought products that have not been licensed for medical use, often intended for recreational use. }\end{array}$ & \\
\hline
\end{tabular}




\begin{tabular}{|c|c|c|}
\hline Theme & Subtheme & Direct quotations that convey themes \\
\hline \multirow{8}{*}{$\begin{array}{l}\text { Child and } \\
\text { family context, } \\
\text { and cannabis } \\
\text { as a last } \\
\text { resort }\end{array}$} & \multirow{3}{*}{$\begin{array}{l}\text { Children's } \\
\text { condition and } \\
\text { severity }\end{array}$} & "Cannabis is the lesser of two evils." (M9) \\
\hline & & "[We were] desperate to try and help our child ... there is no cure for what he has." (M5) \\
\hline & & $\begin{array}{l}\text { "As a parent of a child with a terminal illness, we are more focused on the quality of life.... Sometimes } \\
\text { I felt like our daughter was going to die if we didn't do something about the seizure stuff." (M8) }\end{array}$ \\
\hline & \multirow{3}{*}{$\begin{array}{l}\text { Social } \\
\text { acceptance v. } \\
\text { stigma }\end{array}$} & $\begin{array}{l}\text { "Outside opinions and voices don't really influence my decision .... we are going to do it whether it is } \\
\text { legal or not, whether they like it or not." (F5) }\end{array}$ \\
\hline & & $\begin{array}{l}\text { "I wouldn't tell [my daughter's] grandma, because Grandma would say these are 'bad drugs!' ... If this } \\
\text { drug can help, why not [use it]." (M2) }\end{array}$ \\
\hline & & $\begin{array}{l}\text { "Even though my daughter is only } 5 \text { years old, I want to empower her. I know there is nothing wrong } \\
\text { with [using medical cannabis] ... I am really open about it." (M1) }\end{array}$ \\
\hline & \multirow{2}{*}{$\begin{array}{l}\text { Parental love and } \\
\text { responsibility }\end{array}$} & "I am going to do whatever I have to do to make sure that my child is living a happy life." (M6) \\
\hline & & "What do we have to lose? ... We can only get better." (M7) \\
\hline \multirow{10}{*}{$\begin{array}{l}\text { Varied } \\
\text { information } \\
\text { sources } \\
\text { informed } \\
\text { decision- } \\
\text { making }\end{array}$} & \multirow{2}{*}{$\begin{array}{l}\text { Suppliers and } \\
\text { advocates }\end{array}$} & "All of the information I get from my friends, from Facebook sometimes." (M2) \\
\hline & & $\begin{array}{l}\text { "I told [dispensary owner] what the problem was and he said what we should do and [my child's] } \\
\text { starting dose. He wrote it all down like a prescription so I would be clear on it because it can be a } \\
\text { little overwhelming." (M3) }\end{array}$ \\
\hline & \multirow{2}{*}{$\begin{array}{l}\text { Communication } \\
\text { with health care } \\
\text { providers }\end{array}$} & "I know the doctor doesn't like us to give it to our daughter." (M2) \\
\hline & & $\begin{array}{l}\text { "[Our doctor] can't really describe cannabis right now because of the situation with the government, } \\
\text { but he is very open minded ... he has been monitoring her and I always let him know that this is } \\
\text { what I am doing." (M4) }\end{array}$ \\
\hline & \multirow[t]{2}{*}{$\begin{array}{l}\text { Lack of reliable } \\
\text { information }\end{array}$} & $\begin{array}{l}\text { "If your doctor is not open to talk about it, then your next line of research is the Internet. ... Being } \\
\text { able to decipher biased and unbiased opinions running through parent forums ... is really hard." (M7) }\end{array}$ \\
\hline & & $\begin{array}{l}\text { "If doctors could say, 'okay, go to this link' and they have accurate or resourceful information for you } \\
\text { to read about cannabis, that would be helpful for parents." (M1) }\end{array}$ \\
\hline & \multirow{2}{*}{$\begin{array}{l}\text { Practicalities and } \\
\text { parent expertise }\end{array}$} & "[The product] is $97 \%$ CBD and $3 \%$ THC." (M10) \\
\hline & & $\begin{array}{l}\text { "We administer it via G-tube and we have ... a really fatty substance that we can flush it with. } \\
\text { Apparently the CBD oil needs fat in order to work best." (M6) }\end{array}$ \\
\hline & \multirow[t]{2}{*}{$\begin{array}{l}\text { Need for } \\
\text { research }\end{array}$} & $\begin{array}{l}\text { "I was trying to figure out a dosage and I was being told mixed messages. ... I think I am giving her } \\
\text { enough, but I don't know. ... It would be nice if they could actually do some sort of research where } \\
\text { they can see that her body is changing by using it." (M4) }\end{array}$ \\
\hline & & $\begin{array}{l}\text { "It all really comes down to the lack of research that there is. If you have actual proper research } \\
\text { done, then a reasonable doctor can be convinced that [authorizing cannabis use] is okay." (M7) }\end{array}$ \\
\hline \multirow{3}{*}{$\begin{array}{l}\text { Cannabis as } \\
\text { an ambiguous } \\
\text { medicine }\end{array}$} & & $\begin{array}{l}\text { "It's not even a medication! It's like oil! It's like getting omega-3. ... Just like any other drug, it can } \\
\text { work for some ... it should be one of the medications that [doctors] recommend." (M10) }\end{array}$ \\
\hline & & "Cannabis is just more natural." (M1) \\
\hline & & "Our son is very complex.... He needs real drugs [referring to cannabis]." (F5) \\
\hline \multirow{3}{*}{$\begin{array}{l}\text { Perceived } \\
\text { effects }\end{array}$} & & "We were having $50-80$ [seizures] a day, and on the cannabis we were ... down to 1 a week." (M6) \\
\hline & & $\begin{array}{l}\text { "His mood has greatly improved when I give oil to him. His appetite is improved; his nausea is better." } \\
\text { (M3) }\end{array}$ \\
\hline & & $\begin{array}{l}\text { "My son is already high on all this pharmaceutical shit he has been on, so for me, [adverse effects of } \\
\text { cannabis] don't really make a difference." (M10) }\end{array}$ \\
\hline \multirow{4}{*}{$\begin{array}{l}\text { Legal and } \\
\text { financial } \\
\text { challenges }\end{array}$} & \multirow[t]{2}{*}{$\begin{array}{l}\text { Uncertain } \\
\text { regulations }\end{array}$} & $\begin{array}{l}\text { "[My child's cannabis use] is legal-ish, I think. [Doctors] weren't supposed to give [cannabis } \\
\text { authorization] to us, but they did anyways." (M8) }\end{array}$ \\
\hline & & $\begin{array}{l}\text { I guess the good thing is we can get the product legally, right? ... I guess the next step is ... } \\
\text { somebody has to advocate for getting it covered [by insurance]." (M9) }\end{array}$ \\
\hline & \multirow[t]{2}{*}{ Costs } & $\begin{array}{l}\text { "I am a single mom and it's a huge bill at the end of the month, but I do it because it's saving my } \\
\text { kid's life.... Maybe if it was regulated like a pharmaceutical, I would be able to get it covered and it } \\
\text { would take a huge stress off of me." (M4) }\end{array}$ \\
\hline & & $\begin{array}{l}\text { "It is costing us } \$ 318 \text { a month ... we would really like to double the dose but that would be about } \\
\$ 650 \text {." (M9) }\end{array}$ \\
\hline
\end{tabular}


cannabis may not work for everyone. Parents identified a lack of "empiricism" and hoped for more research to inform dosing and safety.

\section{Cannabis as an ambiguous medicine}

Cannabis was special in that parents viewed it simultaneously as a drug and as an alternative health product. This ambiguity emerged across all interviews. Parents wanted cannabis to be seen as equivalent to the regulated pharmaceuticals their children used, and wished their health care providers would offer it as a treatment option. Some parents equated medical cannabis and standard medical treatments, emphasizing that adverse effects of pharmaceuticals were worse than those of cannabis. Yet, at the same time, families described cannabis as distinct from standard medications, preferring to manage treatments with "more natural" options. Cannabis was an alternative natural health product, but one that still should be offered and prescribed as a standard treatment.

\section{Perceived effects}

Parents described effects and concerns about their child's cannabis use. Two families of children with epilepsy saw no changes despite increasing the dose or switching suppliers. Eight parents noted beneficial effects. Some saw dramatic changes, such as substantial daily reductions in seizures on initiation of cannabis therapies. Others saw improvements but were unsure how much to attribute to cannabis. Most parents described the ability to reduce use of other medications as an important benefit of cannabis. Families of children with cancer were unsure whether cannabis had been effective at reducing tumours, but noted improvements in nausea, pain and appetite.

Five families observed undesired effects, such as fatigue, drowsiness or mild intoxication, but few reported concerns about long- or short-term adverse effects. Adverse effects of cannabis were considered insignificant compared with those of pharmaceuticals or chemotherapy; most parents were entirely unconcerned. Two parents of children with cancer had considered long-term effects on brain development, but concerns were minor given the uncertainty of the disease.

\section{Legal and financial challenges}

Parents described navigating a complex legal environment and financial stress of obtaining cannabis. Challenges primarily related to regulatory concerns that parents felt ultimately limited insurance coverage.

Families lacked a clear process to access medical cannabis legally and felt their child's cannabis use was in a legal "grey area" (subtheme: uncertain regulations). A mother worried substantially about the potential for laws to change if governments changed. Those who obtained cannabis from outside of Canada were concerned about the risk of incarceration, and others worried about online shipments being intercepted at the post office. Inability to travel outside of Canada with their child's medication was another major concern, because it restricted family life.

The amount of money that parents spent on medical cannabis varied based on product and dosing schedule (subtheme: costs), but cost was an important challenge for all families. No insurance providers covered cannabis treatments for children, regardless of source; families paid out of pocket, with costs ranging from $\$ 150$ to more than $\$ 500$ per month. Lack of clear regulations and evidence for medical efficacy were considered barriers to insurance coverage. Two mothers wished they could increase the dose to align with suggestions from health care providers, but costs were prohibitive. Families also expressed frustration that authorized products were taxed like recreational products and found it more affordable to obtain cannabis illegally.

\section{Interpretation}

Our study describes family experiences with medical cannabis for children with severe conditions; our aim was to begin uncovering family practices and attitudes around pediatric medical cannabis. The Canadian context adds a special perspective, as medical and recreational cannabis are legal nationwide, and there are a variety of legal and illegal avenues to access cannabis.

Parents identified substantial challenges, including a lack of reliable information, costs and access to licensed medical products. Importantly, our participants used cannabis in the context of a poorly regulated market, in which industry claims and advertising were widely available without substantiating evidence. Physicians' personal beliefs were another hurdle that families had to navigate alone. These challenges contrasted with strong feelings of hope or praise for products and effects. Willingness to overcome challenges demonstrated the importance of cannabis as a treatment option and reflected parents' sense of responsibility to help their children. Parental desire for health care providers to offer cannabis, alongside their willingness to use it without medical guidance, demonstrated the unique category of medical cannabis: a serious medication that doctors should prescribe, yet still a safe alternative to pursue on one's own. ${ }^{3}$ Despite these conflicting views, parents were disappointed when providers refused to authorize use.

Studies of health care provider perspectives have reported concerns about physical and mental adverse effects of medical cannabis, ${ }^{31-33}$ but our participants reported few of these concerns. Condition severity likely influenced lack of concern, as children of participants had lifelong or terminal conditions. Yet, participants spoke openly about trade-offs when accessing legal or illegal sources. Illegal sources were cheaper and easier to access than legal products but were less trustworthy, likely because they are not subject to rigorous quality and labelling standards for licensed products in Canada. ${ }^{34}$ Others have identified similar parental concerns when accessing cannabis. $3,23,24$

Our findings suggest that some parents will pursue medical cannabis treatments for children despite obstacles, and indicate the need for reliable, unbiased sources of information for parents to access. Resources should reflect the Canadian context of varied product sources and qualities, and highlight the potential competing interest of cannabis 
providers. The abundance of conflicting online information about pediatric medical cannabis ${ }^{5}$ is a result of limited scientific evidence on efficacy and current practices. As such, our findings underscore the need for evidence to inform pediatric guidelines on safety, dosing and products for medical cannabis. Many others have reported similar needs for accurate efficacy, dosing and safety information. ${ }^{4,11,20,22,28,35}$ Robust pharmacologic, clinical and epidemiologic research in these areas will directly address the challenges families identified, and should be a priority of medical and scientific communities.

\section{Limitations}

The small sample from 2 distinct patient groups (epilepsy and cancer) may limit the generalizability of our findings, and differences between groups may not have fully emerged. Selection bias could be another limitation; families who did not feel stigmatized might have been more likely to participate. Furthermore, recall bias may be a limitation due to reliance on self-reporting. We did not speak to children directly, and, notably, we did not speak to adolescents who used cannabis recreationally; this should be a separate project. Reliance on parent reports cannot reflect the patient's own experiences and is therefore limiting. We did not explore parental use of cannabis, and this may be a factor in acceptance; it will be explored in future studies. The requirement to speak English may have limited the participation of immigrant families. We did not pilot the interview guide with families before beginning data collection and we did not achieve data saturation given predetermined sample size, so questions may not capture the entire range of experiences of participants. We did not return transcripts to participants for checking accuracy before analysis so results are limited to the research team's interpretation.

\section{Conclusion}

Parents pursued medical cannabis for children with severe conditions despite obstacles and needed unbiased information to inform decision-making. This study is a first step to inform a larger research program regarding pediatric medical cannabis that includes prevalence surveys, longitudinal observational data collection, pharmacokinetics research, and a national registry and network.

\section{References}

1. Gupta S. Why I changed my mind on weed. CNN; updated 2013 Aug. 8. Available: www.cnn.com/2013/08/08/health/gupta-changed-mind-marijuana/ index.html (accessed 2020 Mar. 5).

2. Rieder MJ; Canadian Paediatric Society, Drug Therapy and Hazardous Substances Committee. Is the medical use of cannabis a therapeutic option for children? Paediatr Child Health 2016;21:31-4.

3. Sobo EJ. Parent use of cannabis for intractable pediatric epilepsy: everyday empiricism and the boundaries of scientific medicine. Soc Sci Med 2017;190: 190-8.

4. Wong SS, Wilens TE. Medical cannabinoids in children and adolescents: a systematic review. Pediatrics 2017;140:e20171818.

5. Yeung M, Wroot $\mathrm{H}$, Charnock C, et al. Cannabis use in pediatric cancer patients: What are they reading? A review of the online literature. Support Care Cancer 2020;28:3503-15.

6. Information for health care professionals: cannabis (marihuana, marijuana) and the cannabinoids. Ottawa: Health Canada; 2018:259. Available: www.canada. $\mathrm{ca} / \mathrm{en} /$ health-canada/services/drugs-medication/cannabis/information-medical -practitioners/information-health-care-professionals-cannabis-cannabinoids.html (accessed 2020 Mar. 5).

7. Pawliuk C, Chau B, Rassekh SR, et al. Efficacy and safety of pediatric medicinal cannabis use: a scoping review. Paediatr Child Health 2020; pxaa031. doi:10.1093/pch/pxaa031. Available: https://academic.oup.com/pch/advance -article/doi/10.1093/pch/pxaa031/5827075 (accessed 2020 May 2).

8. Ali S, Scheffer IE, Sadleir LG. Efficacy of cannabinoids in paediatric epilepsy. Dev Med Child Neurol 2019;61:13-8.

9. Devinsky O, Cross JH, Laux L, et al. Trial of cannabidiol for drug-resistant seizures in the Dravet syndrome. NEngl 7 Med 2017;376:2011-20.

10. McCoy B, Wang L, Zak M, et al. A prospective open-label trial of a CBD/ THC cannabis oil in Dravet syndrome. Ann Clin Transl Neurol 2018;5: 1077-88.

11. Ananth P, Reed-Weston A, Wolfe J. Medical marijuana in pediatric oncology: a review of the evidence and implications for practice. Pediatr Blood Cancer 2018;65 [Epub ahead of print 2017 Sept. 19]. doi: 10.1002/pbc.26826.

12. Tramèr MR, Carroll D, Campbell FA, et al. Cannabinoids for control of chemotherapy induced nausea and vomiting: quantitative systematic review. $B M 7$ 2001;323:16-21

13. Strasser F, Luftner D, Possinger K, et al. Comparison of orally administered cannabis extract and delta-9-tetrahydrocannabinol in treating patients with cancer-related anorexia-cachexia syndrome: a multicenter, phase III, randomized, double-blind, placebo-controlled clinical trial from the Cannabis-In -Cachexia-Study-Group. 7 Clin Oncol 2006;24:3394-400.

14. Johnson JR, Burnell-Nugent M, Lossignol D, et al. Multicenter, double-blind, randomized, placebo-controlled, parallel-group study of the efficacy, safety, and tolerability of THC:CBD extract and THC extract in patients with intractable cancer-related pain. 7 Pain Symptom Manage 2010;39:167-79.

15. Whiting PF, Wolff RF, Deshpande S, et al. Cannabinoids for medical use: a systematic review and meta-analysis. FAMA 2015;313:2456-73.

16. CESAMET ${ }^{\mathrm{TM}}$ (nabilone) Capsules for oral administration FDA. Valeant Pharmaceuticals International; 2006. Available: www.accessdata.fda.gov/drugsatfda docs/label/2006/018677s011lbl.pdf (accessed 2020 Apr. 21).

17. SATIVEX®. Buccal spray cannabinoid analgesic. GW Pharma LTD; 2012. Available: https://pdf.hres.ca/dpd_pm/00016162.PDF (accessed 2021 May 4).

18. Eagland N. BC cracks down on unlicensed pot shops with raids in Victoria and Kamloops Vancouver: Vancouver Sun; updated 2019 Aug. 1. Available: https:// vancouversun.com/cannabis/cannabis-business/b-c-cracks-down-on-unlicensed -pot-shops-with-raids-in-victoria-and-kamloops (accessed 2020 Mar. 4).

19. Rocca R. Toronto using concrete blocks to prevent unlicensed marijuana dispensaries from reopening. Global News; updated 2019 June 8. Available: https:// globalnews.ca/news/5369230/cement-blocks-illegal-marijuana-dispensaries (accessed 2020 Mar. 6).

20. Carter GT, Weydt P, Kyashna-Tocha M, et al. Medicinal cannabis: rational guidelines for dosing. IDrugs 2004;7:464-70.

21. Alcorn J, Vuong S, Wu F, et al. Pediatric dosing considerations for medical cannabis. In: Costain W, editor. Recent advances in cannabinoid research London, UK. London (UK): IntechOpen; 2019:181-200. doi:10.5772/intechopen.85399. Available: www.intechopen.com/books/recent-advances-in-cannabinoid -research/pediatric-dosing-considerations-for-medical-cannabis (accessed 2020 Mar. 6).

22. Klotz KA, Schönberger J, Nakamura L, et al. Expectations and knowledge of cannabidiol therapy for childhood epilepsy - a German caregiver survey. Epilepsy Behav 2020;111:107268. doi: 10.1016/j.yebeh.2020.107268. Available www.sciencedirect.com/science/article/pii/S1525505020304479 (accessed 2020 Aug. 5).

23. Suraev A, Lintzeris N, Stuart J, et al. Composition and use of cannabis extracts for childhood epilepsy in the Australian community. Sci Rep 2018;8:10154. doi: 10.1038/s41598-018-28127-0.

24. Suraev AS, Todd L, Bowen MT, et al. An Australian nationwide survey on medicinal cannabis use for epilepsy: History of antiepileptic drug treatment predicts medicinal cannabis use. Epilepsy Behav 2017;70:334-40.

25. Barchel D, Stolar O, De-Haan T, et al. Oral cannabidiol use in children with autism spectrum disorder to treat related symptoms and co-morbidities. Front Pharmacol 2019;9:1521.

26. Hussain SA, Zhou R, Jacobson C, et al. Perceived efficacy of cannabidiolenriched cannabis extracts for treatment of pediatric epilepsy: a potential role for infantile spasms and Lennox-Gastaut syndrome. Epilepsy Behav 2015;47: $138-41$.

27. Aguirre-Velázquez CG. Report from a survey of parents regarding the use of cannabidiol (medicinal cannabis) in Mexican children with refractory epilepsy. Neurol Res Int 2017;2017:2985729. [Epub ahead of print 2017 Mar 14]. doi: 10.1155/2017/2985729. Available: www.ncbi.nlm.nih.gov/pmc/ articles/PMC5368357 (accessed 2020 Mar. 6).

28. Porter BE, Jacobson C. Report of a parent survey of cannabidiol-enriched cannabis use in pediatric treatment-resistant epilepsy. Epilepsy Behav 2013;29:574-7.

29. NVivo qualitative data analysis software. Version 12. Victoria (AU): QSR International; 2018.

30. Kim H, Sefcik JS, Bradway C. Characteristics of qualitative descriptive studies: a systematic review. Res Nurs Health 2017;40:23-42.

31. McGriff D, Anderson S, Arneson T. Early survey results from the Minnesota Medical Cannabis Program. Minn Med 2016;99:18-22. 
32. 2017 results: Canadian Paediatric Surveillance Program. Ottawa: Public Health Agency of Canada and the Canadian Paediatric Society; 2018:52. Available: www.cpsp.cps.ca/uploads/publications/CPSP-2017-Results_1.pdf (accessed 2020 Mar. 6).

33. Ananth $\mathrm{P}, \mathrm{Ma} \mathrm{C}, \mathrm{Al}-$ Sayegh $\mathrm{H}$, et al. Provider perspectives on use of medical marijuana in children with cancer. Pediatrics 2018;141: e20170559. doi: 10.1542/peds.2017-0559. Available: www.ncbi.nlm.nih.gov/pmc/articles/ PMC5744275 (accessed 2020 Mar. 6).

34. Cannabis legalization and regulation. Ottawa: Department of Justice, Government of Canada; updated 2019 Oct. 17. Available: www.justice.gc.ca/eng/cj-jp/ cannabis (accessed 2020 Mar. 6).

35. Klotz KA, Schulze-Bonhage A, Antonio-Arce VS, et al. Cannabidiol for treatment of childhood epilepsy - a cross-sectional survey. Front Neurol 2018;9: 731. doi: 10.3389/fneur.2018.00731

Affiliations: BC Children's Hospital Research Institute (Gibbard, Mount); Department of Pediatrics (Gibbard, Mount, Rassekh, Siden), Faculty of Medicine, University of British Columbia; BC Children's Hospital (Rassekh, Siden), Vancouver, BC

Contributors: Marissa Gibbard recruited participants, collected data, carried out transcription and analyses, interpreted data, and drafted and revised the manuscript. Dawn Mount recruited participants, collected data, interpreted data, and reviewed and edited the manuscript. Shahrad Rassekh conceptualized and designed the study, interpreted data and critically reviewed the manuscript. Harold Siden conceptualized and designed the study, designed the data collection instruments, interpreted data, advised analyses and manuscript writing, and critically reviewed the manuscript. All authors gave final approval of the version to be published and agree to be accountable for all aspects of the work.

Funding: No external funding was received for this manuscript.

Content licence: This is an Open Access article distributed in accordance with the terms of the Creative Commons Attribution (CC BY-NC-ND 4.0) licence, which permits use, distribution and reproduction in any medium, provided that the original publication is properly cited, the use is noncommercial (i.e., research or educational use), and no modifications or adaptations are made. See: https://creativecommons.org/licenses/ by-nc-nd/4.0/

Data sharing: Data are not available for use by other researchers.

Acknowledgements: The authors thank Christina Han for her assistance analyzing the data, and Colleen Pawliuk for library and informational sciences support, as well as editing. The authors also thank the Evidence to Innovation Theme at BC Children's Hospital Research Institute for supporting this project.

Supplemental information: For reviewer comments and the original submission of this manuscript, please see www.cmajopen.ca/content/9/2/ E563/suppl/DC1. 